\title{
Fusarium solani species complex associated with carapace lesions and branchitis in captive American horseshoe crabs Limulus polyphemus
}

\author{
Kathryn A. Tuxbury ${ }^{1,5, *}$, Gillian C. Shaw ${ }^{2, *}$, Richard J. Montali ${ }^{2}$, Leigh Ann Clayton ${ }^{1}$, \\ Nicole P. Kwiatkowski ${ }^{3}$, Michael J. Dykstra ${ }^{4}$, Joseph L. Mankowski ${ }^{2,3, * *}$ \\ ${ }^{1}$ National Aquarium, Department of Animal Health, 501 East Pratt Street, Baltimore, Maryland 21202, USA \\ ${ }^{2}$ Johns Hopkins University, Department of Molecular and Comparative Pathobiology, 733 N. Broadway, Baltimore, \\ Maryland 21205, USA \\ ${ }^{3}$ Johns Hopkins Microbiology Laboratory, Department of Pathology, Johns Hopkins University School of Medicine, \\ 600 N. Wolfe Street, Baltimore, Maryland 21287, USA \\ ${ }^{4}$ North Carolina State University, College of Veterinary Medicine, 1060 William Moore Drive, Raleigh, \\ North Carolina 27607, USA \\ ${ }^{5}$ Present address: New England Aquarium, 1 Central Wharf, Boston, Massachusetts 02110, USA
}

\begin{abstract}
Captive American horseshoe crabs Limulus polyphemus housed at the National Aquarium presented with a variety of shell and gill lesions over a 3 yr period. Carapace lesions were located on both the dorsal and ventral prosoma and opisthosoma and included multifocal circular areas of tan discoloration, ulcerations, and/or pitting lesions, extending from superficial to full thickness. Gill lesions involved both the book gill cover (operculum) and individual book gill leaflets and included multifocal circular areas of tan discoloration, tan to off-white opaque proliferative lesions, and/or areas of black discoloration. Histopathology revealed fungal hyphae, with variable morphology throughout the thickened and irregular cuticle of the carapace and occasionally penetrating into subcuticular tissues, with associated amebocytic inflammation. Book gill leaflets were infiltrated by fungal hyphae and contained necrotic debris and amebocytes. Thirtyeight of 39 animals ( $97 \%$ ) evaluated via histopathological examination had intralesional fungal hyphae. Fungal cultures of carapace and gill lesions were attempted in 26 tissue samples from 15 individuals and were positive in 13 samples $(50 \%)$, with 10 cultures $(77 \%)$ yielding identification to genus. Fusarium sp. was identified in 8 of the 10 cultures $(80 \%)$ via culture morphology. The Fusarium solani species complex was confirmed in 6 of these $8(75 \%)$ via polymerase chain reaction amplification of 2 different ribosomal-specific sequences of isolated fungal DNA. Antemortem systemic and topical treatments were performed on some affected individuals, but no appreciable change in lesions was observed. Mycotic dermatitis and branchitis are serious health issues for captive American horseshoe crabs.
\end{abstract}

KEY WORDS: Limulus polyphemus $\cdot$ Fusarium solani $\cdot$ Branchitis $\cdot$ Carapace $\cdot$ Fusariosis

\section{INTRODUCTION}

The American horseshoe crab Limulus polyphemus is a chelicerate marine arthropod found in coastal habitats along the Atlantic coast of North America, ranging from Maine to the Yucatan Peninsula. They are well known for their spawning season, when individuals come ashore on beaches by the 1000s to spawn, which, in addition to propagating the species, also provides an important food source for migrating shorebirds (Shuster 1982). The American horseshoe crab is of great importance to the pharmaceutical 
industry. An extract of the horseshoe crab amebocyte Limulus amebocyte lysate is used to test pharmaceuticals (e.g. vaccines, intravenous drugs) and surgical implants for the presence of Gram-negative bacterial endotoxin (Novitsky 1991).

The American horseshoe crab is commonly used in touch tank exhibits in public aquaria, and captive husbandry guidelines have been published (Smith \& Berkson 2005, Smith et al. 2011). Non-infectious diseases of captive horseshoe crabs include traumatic injuries, nutritional deficiencies leading to hypoproteinemia, and ammonia toxicity secondary to poor water quality (Smith 2012). Infectious agents reported in both wild and captive individuals include bacteria, parasites, algae (Leibovitz \& Lewbart 1987), and cyanobacteria (Leibovitz 1986), with shell or carapace disease being a common problem (Smith 2012). Fungal disease has only been reported in captive animals (Leibovitz \& Lewbart 2003, Densmore et al. 2005, Allender et al. 2008, Smith 2012).

Fusarium spp. of fungus are common saprophytes found in soil, air, and water that can be severe plant pathogens (Zhang et al. 2006). Superficial and systemic infections also have been described in a variety of terrestrial and aquatic animal groups, including invertebrates (Burns et al. 1979, Bian \& Egusa 1981, Santana-Neto et al. 2010, Salter et al. 2012), reptiles (Cabañes et al. 1997, Rose et al. 2001, Dadone et al. 2010, Sarmiento-Ramírez et al. 2010, Williams et al. 2012), amphibians (Perpiñán et al. 2010), fish (Ostland et al. 1987, Smith et al. 1989, Crow et al. 1995), marine mammals (Montali et al. 1981, Frasca et al. 1996, Clauss et al. 2008, Staggs et al. 2010, Naples et al. 2012, Tanaka et al. 2012), and domestic animals (Evans et al. 2004, Namitome et al. 2011). Fusariosis in humans may be disseminated or locally invasive and usually causes disease in immunocompromised patients (Hiemenz et al. 1990, Gupta et al. 2000, Anaissie et al. 2001, Dignani \& Anaissie 2004, Gutiérrez Paredes et al. 2011).

This report describes carapace and gill lesions and histopathology associated with cutaneous mycotic infections in a collection of captive horseshoe crabs.

\section{MATERIALS AND METHODS}

\section{Animal housing and care}

A retrospective review was conducted of mortality in adult horseshoe crabs Limulus polyphemus at the National Aquarium (NA) from 27 June 2006 to 18 June 2009. Horseshoe crabs were tracked as individuals starting in January 2006. For individual identification, each animal was tagged with a unique 3-digit number on a small oval 1/8 $\times 1 / 4 \mathrm{in} .(\sim 3 \times 6 \mathrm{~mm})$ plastic fish tag (Floy Tag \& Mgf.) adhered to either the right or left corner of the prosoma with marine epoxy. Adult animals in terminal molt were obtained from multiple off-site suppliers throughout the year. Time in terminal molt could not be definitively determined. However, based on carapace condition and epibiota, some horseshoe crabs may have been in the terminal molt stage for multiple years, using previously published standards for aging (Shuster \& Sekiguchi 2003). A 30 to $90 \mathrm{~d}$ observational quarantine was performed for all individuals. Physical examinations were performed approximately every 1 to 3 mo. Mean longevity of horseshoe crabs at NA was determined from date of arrival to date of death in months.

Horseshoe crabs were housed in 3 different artificial-saltwater, closed-re-circulating, mixed-invertebrate-species systems: a quarantine tank, a holding tank for educational program use, and a touch tank exhibit with adjacent and connected backup holding tanks. The animals were housed on gravel/crushed coral substrate, fed on shrimp, smelt, and mussels, and received vitamin/mineral supplementation twice weekly orally in food. Other animals housed in these systems included whelks (Busycon spp.), mud snails (Nassarius obsoletus), slate-pencil urchins (Eucidaris tribuloides), hermit crabs (Clibinarius vittatus, Pagurus spp.), green crabs (Carcinus sp.), and/or bay sea stars (Asterias forbesi). Tank temperatures ranged from 17.2 to $22.8^{\circ} \mathrm{C}$ and salinity ranged from 27 to 37 ppt. On exhibit, visitors were able to touch the top of the shell of individual horseshoe crabs with 2 fingers with animals kept underwater. Animals taken off-site for educational programs were also handled by the general public. Individuals used for the touch exhibit were typically on a rotation of $1 \mathrm{wk}$ on-exhibit followed by 2 wk off-exhibit in backup holding tanks.

\section{Histopathology evaluation}

At post-mortem examinations of animals euthanized or found dead, tissues were immersion fixed in $10 \%$ neutral-buffered formalin. Shell and limbs required softening in Formical ${ }^{\circledR}$ (Decal Chemical Corporation) before trimming and sectioning. Sections were stained with hematoxylin and eosin for routine histologic review; additional sections were stained by periodic acid-Schiff (PAS) or Gomori's methenamine silver (GMS) histochemical stains to illustrate fungal morphology. 


\section{Fungal cultures and molecular diagnostics}

A total of 26 different fungal cultures were performed on 15 individuals. The majority of culture samples were taken post-mortem, but 5 individuals had tissues sampled ante-mortem. Book gill tissue, including operculum (book gill cover) and/or gill leaflets, was most commonly sampled $(\mathrm{n}=19)$; shell (carapace) $(\mathrm{n}=5)$, hepatopancreas $(\mathrm{n}=1)$, and tail muscle $(n=1)$ were also cultured.

Fungal cultures were performed at 3 different laboratories. The majority of cultures were initially started at NA's laboratory in Sabouraud's dextrose agar (SAB) media at 22 to $23^{\circ} \mathrm{C}$. Positive cultures were subsequently submitted to either North Carolina State University's (NCSU) Mycology Laboratory or to Johns Hopkins University's (JHU) Department of Pathology for identification. In addition, some fresh tissues were submitted directly to either NCSU or JHU for both culture and identification. At NCSU, cultures received on SAB were subcultured onto $\mathrm{CM}^{+}$agar plates $\left(17 \mathrm{~g} \mathrm{BBL}^{\mathrm{TM}}\right.$ corn meal agar, $0.1 \mathrm{~g}$ streptomycin sulfate, $0.1 \mathrm{~g}$ penicillin $\mathrm{G}$, dissolved in 11 distilled water) and incubated at room temperature. When sporulation was observed, tape lifts were made of the culture surface and put into lactophenol cotton blue, followed by light microscope examination to identify the types of spores present for identification to genus. At JHU, fresh samples were cultured on SAB with gentamicin (50 $\mathrm{mg} \mathrm{l}^{-1}$ ) and identified to genus using morphological characteristics and DNA sequencing.

Fungal DNA was isolated using the Zymo Research ZR Fungal DNA Kit ${ }^{\mathrm{TM}}$ following manufacturer's tinstructions. Two different ribosomal specific sequences, the rDNA 25-28s region and the rDNA internal transcribed spacer region (ITS), were amplified using polymerase chain reaction (PCR). Primer sequences for the rDNA 25-28s region were NL1 (5'-GCA TAT CAA TAA GCG GAG GAA AAG-3') and NL4 (5'-GGT CCG TGT TTC AAG ACG C-3') and primers for the ITS were ITS1 (5'-TCC GTC GGT GAA CCT GCG G-3') and ITS2 (5'-TCC TCC GCT TAT TGA TAT GC-3'). Amplicons were sequenced, and sequences were compared to known rDNA sequences of Fusarium sp. to speciate the isolates (Kwiatkowski et al. 2012).

\section{RESULTS}

\section{Case history}

Eighty horseshoe crabs (Limulus polyphemus) died during the 3 yr period from June 2006 to June 2009; 46 of these were euthanized due to the extent of disease, 33 were found dead, and 1 individual's death event was unrecorded. Seventy-eight of 80 individuals $(98 \%)$ that died in the 3 yr study period had longevity calculated in months from date of arrival to date of death. Two individuals had unknown arrival dates and were thus excluded. Mean longevity at the NA was 10.5 mo (SD: 7.4, range: 0.2 to 33.2).

Post-mortem examinations were performed on 59 of 80 animals (74\%), representing all individuals that were not severely autolyzed at the time of presentation. Both gross necropsy and cytological analyses of lesions were performed. Of the 59 animals necropsied, 39 (66\%) underwent histopathologic evaluation of both normal-appearing and diseased tissues. Aerobic bacterial and fungal cultures were performed on lesions of gill, carapace, and/or internal organs (hepatopancreas) in a subset of these animals.

\section{Gross lesions}

All horseshoe crabs presented with tan lesions on single to multiple body parts, including dorsal and ventral carapace, opercula and book gill leaflets, appendages, and arthrodial membrane (Figs. 1 \& 2).

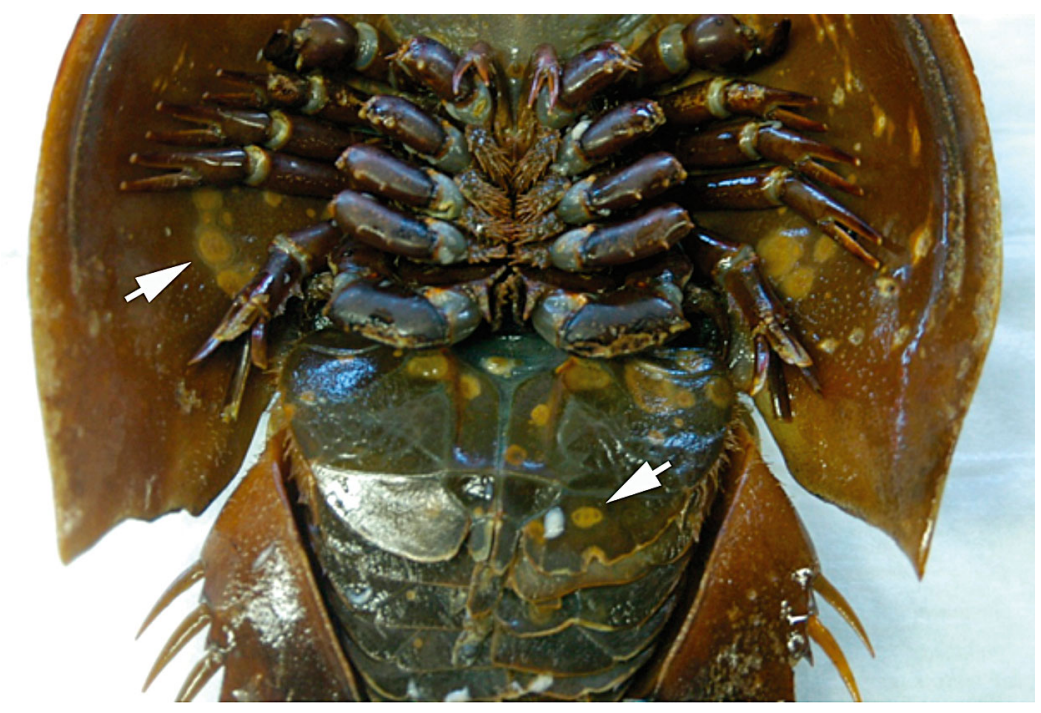

Fig. 1. Limulus polyphemus. Ventral view of an affected horseshoe crab showing multifocal circular, tan coalescing lesions on both carapace and book gill covers (opercula; white arrows) 

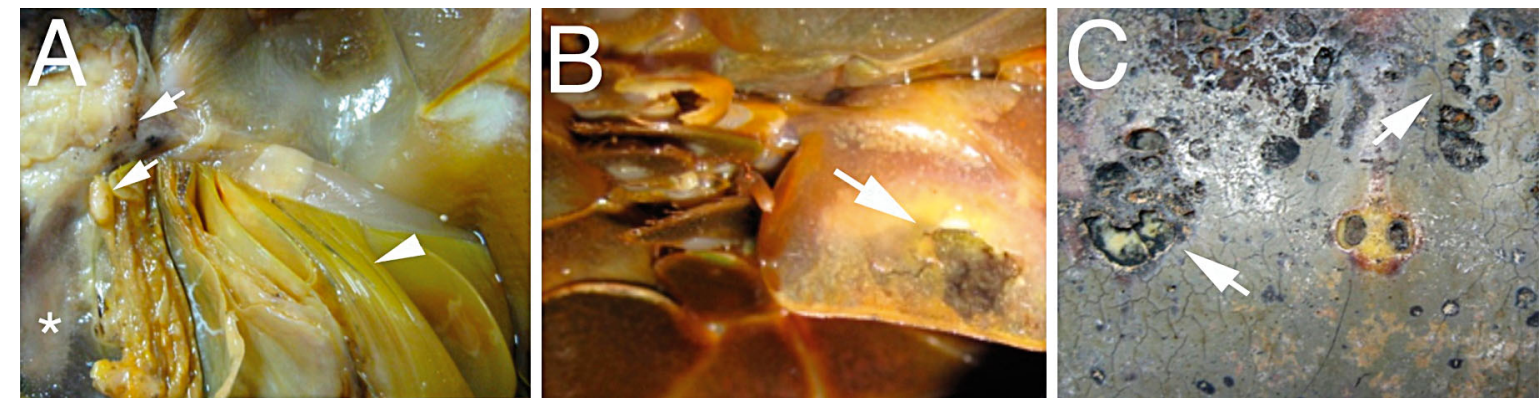

Fig. 2. Limulus polyphemus. Variety of gross lesions on affected horseshoe crabs. (A) Ventral view of horseshoe crab showing reflected book gill cover (operculum; white asterisk) and gill leaflets (white arrowhead), with opaque, tan proliferative lesions (white arrows). Affected gill leaflets were very friable and some were missing in this individual. (B) This operculum lesion is discolored black and surrounded with tan tissue (white arrow). (C) Dorsal view of horseshoe crab carapace showing multifocal pitting lesions with black and tan discoloration (white arrows)

There were tan discolorations on the book gill cover (operculum) (Fig. 1) and opaque, pale tan proliferative lesions on both the operculum and gill leaflets (Fig. 2A), as well as opaque, tan and/or black discoloration of the operculum and gill leaflets (Fig. 2B). Affected leaflets were friable, and leaflets were often missing from affected crabs. Carapace lesions ranged from multifocal circular, tan coalescing lesions (Fig. 1) to pitting lesions with black and tan discoloration (Fig. 2C) to multifocal erosive lesions, ranging from small to very expansive and affecting most of the carapace surface (not shown). Appendage lesions included erosions and proliferative opaque, tan lesions at joints. Occasionally the telson muscle and/or arthrodial membrane were tan in color, with an irregular, tattered surface and muscle loss.

\section{Histopathology findings}

Thirty-eight of 39 (97\%) individuals had microscopic evidence of fungal disease, affecting gills and/ or carapace. Lesions involving the carapace and operculum (book gill cover) typically consisted of a thickened and irregular cuticle, with numerous penetrating fungal hyphae. The surface of the involved cuticle was often irregular and occasionally lacked the epicuticle (erosion). Affected cuticle often had a mixed bacterial population, consisting of Gramnegative and Gram-positive rods and cocci (biofilm). In severe lesions, the regular cuticular architecture was replaced with brightly eosinophilic necrotic tissue and mats of hyphae. Where fungal hyphae had completely penetrated the cuticle and reached into the sub-cuticular tissues, tissue architecture was disrupted by abundant intact and degranulated amebocytes, brightly eosinophilic hyaline material (clotted hemolymph), and acellular necrotic debris (Fig. 3A-C). Involved subcuticular tissues included spongy parenchymal connective tissue, striated muscle, digestive gland, and gonads.

Book gills are delicate structures covered with a thin cuticle and have a central vascular channel through which hemolymph and amebocytes flow (Fig. 3A). Affected gill leaflets had invasive fungal hyphae penetrating an expanded cuticle. The vascular channels were expanded by abundant intact and degranulated amebocytes, brightly eosinophilic hyaline material, and acellular necrotic debris (Fig. 3A,B). Affected leaflets were also often covered with a surface biofilm containing bacteria and occasional fungal hyphae.

GMS and PAS staining demonstrated variable fungal morphology. Most hyphae were 4 to $7 \mu \mathrm{m}$ in diameter and septate, with parallel walls and non-dichotomous acute and right-angle branching. Occasionally, hyphae had non-parallel walls, while other hyphae were 2 to $3 \mu \mathrm{m}$ in diameter, with variable branching patterns and septation (Fig. 3D). Other findings include necrotizing myositis and cellulitis, hepatopancreatitis, and encysted metazoan parasites.

\section{Fungal culture and PCR findings}

Fungal cultures were performed to establish identity of the fungal hyphae. Thirteen of 26 submitted fungal cultures were positive for growth $(50 \%)$, with 10 of 13 positive cultures $(77 \%)$ having organisms classified to at least the genus level based on culture characteristics. Fusarium sp. was identified in 8 of these 10 identified fungal cultures $(80 \%)$, based on characteristics including hyaline and septate vegeta- 


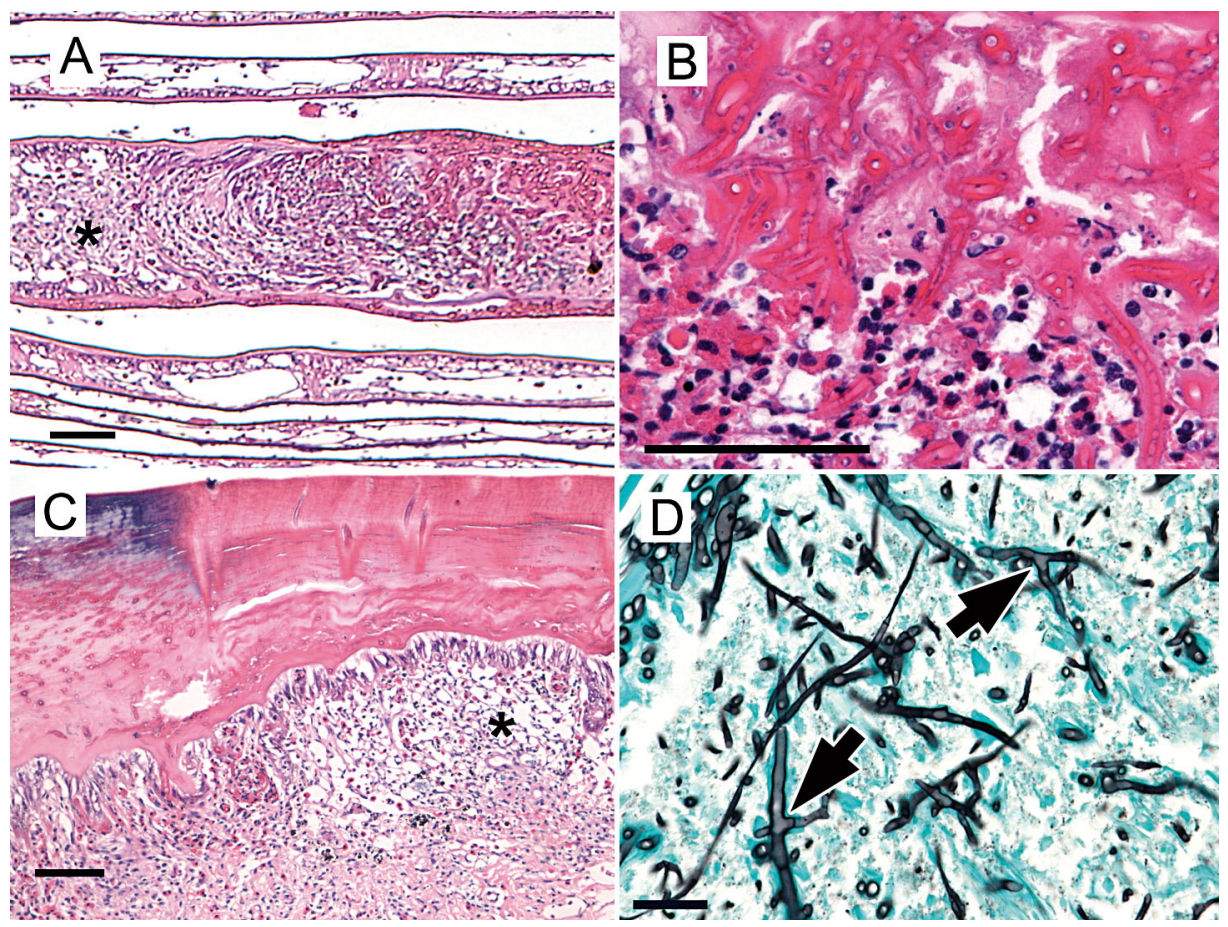

Fig. 3. Limulus polyphemus. Microscopic lesions from horseshoe crabs with fungal infections that were identified as Fusarium solani species complex. (A) Cross sections of book gill leaflets. An expanded affected leaflet (center, *) is surrounded by normal leaflets that have clear central vascular channels, with occasional viable amebocytes. In contrast, the cuticle of the damaged leaflet is thickened by abundant fungal hyphae that penetrate into and traverse the expanded central vascular channel, which also contains viable and degenerate amebocytes and acellular eosinophilic necrotic debris. Hematoxylin \& eosin (H\&E) stain. (B) Higher magnification of affected book gill leaflet illustrates abundant degranulated amebocytes surrounding invasive fungal hyphae. Hyphae are 4 to $7 \mu \mathrm{m}$ in diameter and septate, with regular, parallel walls. H\&E stain. (C) Cross section of operculum. The cuticle of the operculum is expanded and has abundant penetrating fungal hyphae. Underlying normal spongy parenchymal connective tissue $(*)$ consists of clear spaces, with occasional viable amebocytes, and is surrounded by abnormal, dense parenchyma containing necrotic eosinophilic debris and degenerate amebocytes. H\&E stain. (D) Cross section of gill leaflet demonstrates numerous penetrating septate fungal hyphae that are 2 to $7 \mu \mathrm{m}$ in diameter, with parallel walls and both acute and right-angle branching (black arrows). Gomori's methenamine silver stain. Scale bars $=(\mathrm{A}, \mathrm{C}) 100 \mu \mathrm{m}$,

(B) $50 \mu \mathrm{m}$, (D) $25 \mu \mathrm{m}$

tive hyphae bearing unbranched conidiophores with curved fusiform macroconidia (8 to $16 \times 2$ to $4.5 \mu \mathrm{m}$ ) with 3 to 5 septa. Six of 8 Fusarium sp. cultures $(75.0 \%)$ were identified as the Fusarium solani species complex based on rDNA ITS region and 25-28s target sequencing, with similarity indexes of 99.65 and $100 \%$, respectively (GenBank Accession Numbers KF985243 and KF985244). The 2 other fungal species isolated from gill lesions and identified via culture morphology were Hortea werneckii and Stemphylium sp.

\section{DISCUSSION}

In this collection of horseshoe crabs Limulus polyphemus, fungal hyphae penetrated the carapace and book gill cuticle, invading underlying tissue and causing visible lesions. In tissues, the predominant morphology of fungal hyphae was suggestive of Fusarium sp., with parallel walls that ranged from 2 to $7 \mu \mathrm{m}$ in diameter, with both acute and right angle branching. The identity of the fungal pathogen was confirmed as the Fusarium solani species complex via culture followed by PCR to identify rDNA specific sequences. It is difficult to identify fungi in tissue section based on morphology alone, and identification should be confirmed by additional techniques. The morphology of the hyphae in these horseshoe crabs was variable and not entirely consistent with accepted descriptions of Fusarium spp. However, like the fungal pathogen recently reported in lined seahorses (Salter et al. 2012), although the hyphal morphology was variable, the identification of Fusarium sp. was confirmed by fungal culture and sequencing fungal DNA. 
Possible sources of fungal organisms include the water, substrate, and other animals housed with the horseshoe crabs. One possible route of fungal infection is entry through pre-existing traumatic injuries of the carapace and/or book gill surface. Individuals also may have been immune-suppressed secondary to stress of captivity and/or suboptimal environmental parameters that predisposed them to disseminated fusariosis. While immune status in this population was not investigated, hemolymph protein levels could be evaluated in future studies, as panhypoproteinemia may be correlated with reduced immune function (Nolan \& Smith 2009). Systemic disease was supported by generalized inflammation and necrosis found in additional tissues, including striated muscles, digestive gland, testis and ovary, and spongy parenchyma.

Microscopic lesions were typified by involvement of the horseshoe crab's only blood cell, the amebocyte (also called the hemocyte). This is a large round to irregularly shaped cell ( 7 to $11 \mu \mathrm{m}$ in diameter), with abundant cytoplasm containing coarse bright red granules and a single dark, basophilic nucleus. The amebocyte responds to pathogens by release of granules that contain antimicrobial and coagulation proteins, forming a clot (Iwanaga \& Lee 2005). The inflammatory response was characterized by large numbers of amebocytes accompanied by necrosis. A similar response is described in Kuruma prawn, with hyphae surrounded by hemocytes and debris from coagulation necrosis (Bian \& Egusa 1981).

Several affected individuals were treated antemortem with systemic and topical antibiotics and antifungal drugs. Oxytetracycline (Bio-Mycin 200, Boeheringer Ingleheim Vetmedica) was administered intravascularly and itraconazole (Sporanox, Janssen Pharmaceutica) was administered orally via a red rubber catheter based on pharmacokinetic studies of these drugs in horseshoe crabs (Nolan et al. 2007, Allender et al. 2008). Also, a variety of different topical treatments were performed. Topical treatments included cleaning carapace lesions with Tricide ear cleaner (Molecular Therapeutics) or chlorhexidine scrub (ChlorHex-Q, Vedco) and/or applying $1 \%$ silver sulfadiazine cream (SSD, Watson Pharmaceuticals) to carapace and limb lesions. Occasionally proliferative lesions involving limbs and/or the operculum were surgically excised. In general, treatments were considered unsuccessful as lesions never resolved and the histopathology later revealed that the fungal organisms had already deeply invaded the carapace and gills by the time lesions were grossly evident. Newer azole anti-fungal drugs such as voriconazole and posaconazole may offer better treatment options for disseminated and cutaneous Fusarium solani species complex infections in both human and veterinary medical fields (Clauss et al. 2008, Wiederhold et al. 2010, Muhammed et al. 2011, Naples et al. 2012).

This study was part of an in-house review of horseshoe crab husbandry and health conducted by the animal care staff. Ultimately, the touch pool was closed, and this reduced the need for animal acquisitions and correlated with somewhat increased longevity. However, in many cases, animals appeared to be ill at the time of acquisition based on physical exam findings (e.g. shell disease, poor muscle strength), and this may compromise longevity and be unrelated to in-house husbandry standards. Comparative longevity information for captive horseshoe crabs used in public programming is not readily available. Many public aquarium veterinarians indicate 2 to $3 \mathrm{yr}$ is common; however, few facilities appear to track animals as individuals or monitor mortality rates and longevity in detail (L. A. Clayton pers. obs.). Standards for aquatic invertebrate medicine and care continue to advance as greater focus is placed on appropriate welfare for invertebrates housed in captive settings. The NA animal care staff continues to revise husbandry and handling protocols (e.g. less abrasive substrates, increased commercial diet utilization, animals collected from the wild by NA to control shipment conditions).

The presence of fungal infections in this collection of horseshoe crabs may have implications for their use in touch tank and other handling programs. While it is unknown if zoonotic transmission is possible, fusariosis in humans has been reported, suggesting that animals with obvious shell disease should be removed from touch programs. Mycotic shell and gill disease consistent with fusariosis was associated with significant morbidity and mortality in captive horseshoe crabs at the NA, and management strategies to monitor disease conditions and track mortality rates and longevity are warranted in captive settings.

Acknowledgements. We thank the aquarists at the National Aquarium for their diligent animal care, and Dr. M. Allender for consultation on horseshoe crab treatments and clinical findings at another institution. Also, we are grateful to Dr. S. Gore for her help with initiation of detailed record keeping of horseshoe crabs at the National Aquarium, and to Dr. W. Merz (Johns Hopkins Hospital Microbiology Laboratory) for assistance with fungal identification. Thanks to Dr. S. Frasca (Connecticut Veterinary Medical Diagnostic Laboratory) for assistance with histopathology, and to Dr. Ben Rossi for reviewing the manuscript. Thanks to all of the veterinary pathology trainees and pathologists at Johns Hopkins University who processed the horseshoe crab cases. 


\section{LITERATURE CITED}

- Allender MC, Schumacher J, Milam J, George R, Cox S, Martín-Jiménez T (2008) Pharmacokinetics of intravascular itraconazole in the American horseshoe crab (Limulus polyphemus). J Vet Pharmacol Ther 31:83-86

Anaissie EJ, Kuchar RT, Rex JH, Francesconi A and others (2001) Fusariosis associated with pathogenic Fusarium species colonization of a hospital water system: a new paradigm for the epidemiology of opportunistic mold infections. Clin Infect Dis 33:1871-1878

- Bian BZ, Egusa S (1981) Histopathology of black gill disease caused by Fusarium solani (Martius) infection in the Kuruma prawn, Penaeus japonicas Bate. J Fish Dis 4: 195-201

Burns CD, Berrigan ME, Henderson GE (1979) Fusarium sp. infections in the freshwater prawn Macrobrachium rosenbergii (De Man). Aquaculture 16:193-198

Cabañes FJ, Alonso JM, Castellá G, Alegre F, Domingo M, Pont S (1997) Cutaneous hyalohyphomycosis caused by Fusarium solani in a loggerhead sea turtle (Caretta caretta L.). J Clin Microbiol 35:3343-3345

Clauss TM, Walsh MT, Camus AC, Dove ADM (2008) Resolution of cutaneous Fusarium solani infection in a beluga whale (Delphinapterus leucas) following aggressive wound management, and oral voriconazole therapy. In: Proceedings of the 39th International Association of Aquatic Animal Medicine, 10-14 May 2008, Pomezia, Rome. Omnipress, Madison, WI (Abstract)

Crow GL, Brock JA, Kaiser S (1995) Fusarium solani fungal infection of the lateral line canal system in captive scalloped hammerhead sharks (Sphyma lewini) in Hawaii. J Wildl Dis 31:562-565

Dadone LI, Klaphake E, Garner MM, Schwahn D and others (2010) Pituitary cystadenoma, enterolipidosis, and cutaneous mycosis in an Everglades ratsnake (Elaphe obsoleta rossalleni). J Zoo Wildl Med 41:538-541

Densmore C, Crawford E, Smith D, Dykstra M (2005) Probable branchiomycosis among a captive population of horseshoe crabs, Limulus polyphemus, from Delaware Bay. In: Proceedings of the 30th eastern fish health workshop 13-17 Jun 2005, Shepherdstown, WV. National Fish Health Research Laboratory, Kearneysville, WV (Abstract)

> Dignani MC, Anaissie E (2004) Human fusariosis. Clin Microbiol Infect 10:67-75

Evans J, Levesque D, De Lahunta A, Jensen HE (2004) Intracranial fusariosis: a novel cause of fungal meningoencephalitis in a dog. Vet Pathol 41:510-514

Frasca S Jr, Dunn JL, Cooke JC, Buck JD (1996) Mycotic dermatitis in an Atlantic white-sided dolphin, a pygmy sperm whale, and two harbor seals. J Am Vet Med Assoc 208:727-729

Gupta AK, Baran R, Summerbell RC (2000) Fusarium infections of the skin. Curr Opin Infect Dis 13:121-128

> Gutiérrez Paredes EM, Gámez Pérez L, González Rodríguez AJ, Ramón Quiles D, Monteagudo Castro C, Jordá Cuevas E (2011) Disseminated fusariosis in immunocompromised patients. Eur J Dermatol 21:753-755

> Hiemenz JW, Kennedy B, Kwon-Chung KJ (1990) Invasive fusariosis associated with an injury by a stingray barb. J Med Vet Mycol 28:209-213

> Iwanaga S, Lee BL (2005) Recent advances in the innate immunity of invertebrate animals. J Biochem Mol Biol 38: $128-150$
Kwiatkowski NP, Babiker WM, Merz WG, Carroll KC, Zhang SX (2012) Evaluation of nucleic acid sequencing of the D1/D2 region of the large subunit of the 28S rDNA and the internal transcribed spacer region using SmartGene IDNS software for identification of filamentous fungi in a clinical laboratory. J Mol Diagn 14:393-401

Leibovitz L (1986) Cyanobacterial diseases of the horseshoe crab (Limulus polyphemus). Biol Bull 171:482-483

Leibovitz L, Lewbart GA (1987) A green algal (chlorophycophytal) infection of the dorsal surface of the exoskeleton and associated organ structures in the horseshoe crab (Limulus polyphemus). Biol Bull 173:430

Leibovitz L, Lewbart GA (2003) Diseases and symbionts: vulnerability despite tough shells. In: Shuster CN, Barlow RB, Brockmann HJ (eds) The American horseshoe crab. Harvard University Press, Cambridge, MA, p 245-275

> Montali RJ, Bush M, Strandberg JD, Janssen DL, Boness DJ, Whitla JC (1981) Cyclic dermatitis associated with Fusarium sp infection in pinnipeds. J Am Vet Med Assoc 179: 1198-1212

> Muhammed M, Coleman JJ, Carneiro HA, Mylonakis E (2011) The challenge of managing fusariosis. Virulence 2:91-96

> Namitome K, Kano R, Sekiguchi M, Iwasaki T, Kaneshima T, Nishifuji K (2011) Isolation of Fusarium sp. from a claw of a dog with onychomycosis. J Vet Med Sci 73:965-969

> Naples LM, Poll CP, Berzins IK (2012) Successful treatment of a severe case of fusariomycosis in a beluga whale (Delphinapterus leucas leucas). J Zoo Wildl Med 43:596-602

Nolan MW, Smith SA (2009) Clinical evaluation, common diseases and veterinary care of the horseshoe crab, Limulus polyphemus. In: Tanacredi JT, Botton ML, Smith DR (eds) Biology and conservation of horseshoe crabs. Springer, New York, NY, p 479-499

Nolan MW, Smith SA, Jones D (2007) Pharmacokinetics of oxytetracycline in the American horseshoe crab, Limulus polyphemus. J Vet Pharmacol Ther 30:451-455

Novitsky TJ (1991) Discovery to commercialization: the blood of the horseshoe crab. Oceanus 27:13-18

> Ostland VE, Ferguson HW, Armstrong RD, Asselin A, Hall R (1987) Case report: granulomatous peritonitis in fish associated with Fusarium solani. Vet Rec 121:595-596

Perpiñán D, Trupkiewicz JG, Armbrust AL, Geiser DM, Armstrong S, Garner MM, Armstrong DL (2010) Dermatitis in captive Wyoming toads (Bufo baxteri) associated with Fusarium spp. J Wildl Dis 46:1185-1195

> Rose FL, Koke J, Koehn R, Smith D (2001) Identification of the etiological agent for necrotizing scute disease in the Texas tortoise. J Wildl Dis 37:223-228

Salter CE, O'Donnell K, Sutton DA, Marancik DP and others (2012) Dermatitis and systemic mycosis in lined seahorses Hippocampus erectus associated with a marineadapted Fusarium solani species complex pathogen. Dis Aquat Org 101:23-31

Santana-Neto PL, Albuquerque CMR, Silva APP, Svedese VM, Lima EALA (2010) Natural occurrence of the Fusarium solani on Tityus stigmurus (Thorell, 1876) (Scorpiones: Buthidae). Braz J Biol 70:151-153

Sarmiento-Ramírez JM, Abella E, Martín MP, Tellería MT, López-Jurado LF, Marco A, Diéquez-Uribeondo J (2010) Fusarium solani is responsible for mass mortalities in nests of loggerhead sea turtle, Caretta caretta, in Boavista, Cape Verde. FEMS Microbiol Lett 312:192-200

Shuster CN (1982) A pictorial review of the natural history 
and ecology of the horseshoe crab, Limulus polyphemus, with reference to other Limulidae. In: Bonaventura J, Bonaventura C, Tesh S (eds) Physiology and biology of the horseshoe crabs: studies on normal and environmentally stressed animals. Alan R. Liss, New York, NY, p 1-52 Shuster CN, Sekiguchi (2003) Growing up takes about ten years and eighteen stages. In: Shuster CN, Barlow RB, Brockmann HJ (eds) The American horseshoe crab. Harvard University Press, Cambridge, MA, p 103-130

Smith SA (2012) Horseshoe crabs. In: Lewbart GA (ed) Invertebrate medicine. John Wiley \& Sons, Ames, IA, p 173-185

Smith SA, Berkson J (2005) Laboratory culture and maintenance of the horseshoe crab (Limulus polyphemus). Lab Anim (NY) 34:27-34

Smith AG, Muhvich AG, Muhvich KH, Wood C (1989) Fatal Fusarium solani infections in baby sharks. J Med Vet Mycol 27:83-91

Smith SA, Scimeca JM, Mainous ME (2011) Culture and maintenance of selected invertebrates in the laboratory and classroom. ILAR J 52:153-164

Editorial responsibility: Rebecca Gast, Woods Hole, Massachusetts, USA
Staggs L, St. Leger J, Bossart G, Townsend FI Jr, Hicks C, Rinaldi M (2010) A novel case of Fusarium oxysporum infection in an Atlantic bottlenose dolphin (Tursiops truncatus). J Zoo Wildl Med 41:287-290

Tanaka M, Izawa T, Kuwamura M, Nakao T and others (2012) Deep granulomatous dermatitis of the fin caused by Fusarium solani in a false killer whale (Pseudorca crassidens). J Vet Med Sci 74:779-782

> Wiederhold NP, Najvar LK, Bocanegra R, Graybill JR, Patterson TF (2010) Efficacy of posaconazole as treatment and prophylaxis against Fusarium solani. Antimicrob Agents Chemother 54:1055-1059

Williams SR, Sims MA, Roth-Johnson L, Wickes B (2012) Surgical removal of an abscess associated with Fusarium solani from a Kemp's ridley sea turtle (Lepidochelys kempii). J Zoo Wildl Med 43:402-406

Zhang N, O'Donnell K, Sutton DA, Nalim FA, Summerbell RC, Padhye AA, Geiser DM (2006) Members of the Fusarium solani species complex that cause infections in both humans and plants are common in the environment. J Clin Microbiol 44:2186-2190

Submitted: October 14, 2013; Accepted: May 12, 2014 Proofs received from author(s): May 22, 2014 